\title{
Study on Application of ARCS Motivational Model on Cross-Border E-Commerce Course Design
}

\author{
Xueqing $\mathrm{Zhou}^{1,} \mathrm{Yu} \mathrm{He}^{1 *}$ \\ ${ }^{1}$ School of Foreign Languages, Xinhua College of Sun Yat-sen University, Guangzhou, Guangdong 510520, China \\ *Corresponding author. Email: hedyfao@126.com
}

\begin{abstract}
The robust development of Cross-border E-commerce (hereinafter as CBEC) has greatly boosted the global economy, accompanied by researches on cultivation of talents needed in CBEC. The cultivation largely depends on the school course designs. The authors conduct a case study of a college in China combined with quantitative questionnaire to analyse the effects of CBEC course design on the basis of ARCS model. The study results show that the four strategies based on ARCS model are proved to be fairly effective. Most students respond well to the teaching strategies. Thus, this study has extended the study of ARCS model to a fresh education context and offers some insights for the research in teaching of CBEC courses.
\end{abstract}

Keywords: CBEC, instructional design, ARCS model

\section{INTRODUCTION}

CBEC in China has witnessed rapid development since the launch of "the Road and Belt Initiative" and "Internet Plus". In 2018, the gross volume of CBEC in China has reached over 1, 000 billion dollars, with growth rate of $11.4 \%$. The rapid development of CBEC, on the one hand, has enriched the relevant studies from logistics [1-4], market [5], to customers [7]. On the other hand, the shortage of talents in CBEC is gradually recognized [8]. The recruitment of graduates in return drives many colleges and vocational schools to set relevant CBEC courses so as to satisfy the needs in society. The research focus is also shifted from the e-commerce itself to the instruction of CBEC courses. How to design the syllabus, employ teaching tactics, motivate and cultivate qualified graduates is definitely worth exploring. Thus, this study follows this trend on the course design of CBEC and analyse its effects on the basis of ARCS motivational model.

\section{LITERATURE REVIEW}

When it comes to the study of motivation, it is widely acknowledged that numerous researches from different perspectives can be found such as educational psychology [9], social psychology [10] and educational studies [11-12]. Among the educational studies, Keller firstly introduced the ARCS motivational model in 1984 [11] and there are many subsequent studies that describe the model. There are four categories: Attention, Relevance, Confidence and Satisfaction. Attention means capturing the interest of learners and stimulating the curiosity to learn; relevance refers to meeting the personal needs/goals of the learner to effect a positive attitude; confidence is concerned with helping the learners believe/feel that they will succeed and control their success; satisfaction is defined as reinforcing accomplishment with rewards (internal and external) [12]. Each of the four categories has subcategories based on the major motivational variables subsumed by the categories [12]. The subcategories of ARCS model can be seen in Table 1.

Table 1 Subcategories of ARCS model

\begin{tabular}{l|l}
\hline Category & Sub-categories \\
\hline Attention & A1: Perceptual Arousal \\
Getting & A2: Inquiry Arousal \\
strategies & A3: Variability \\
\hline Relevance & R1: Goal Orientation \\
Producing & R2: Motive Matching \\
Strategies & R3: Familiarity \\
\hline Confidence & C1: Learning Requirements \\
Building & C2: Success Opportunities \\
Strategies & C3: Personal Control \\
\hline Satisfaction-G & S1: Natural Consequences \\
enerating & S2: Positive Consequences \\
Strategies & S3: Equity \\
\hline
\end{tabular}

These subcategories could help diagnose learners' motivational profiles and create motivational tactics that are proper for the specific problems identified [12]. The ARCS model emphasizes not only the stimulating of learners' motivation, but the sustaining of motivation so that it could provide learners with fulfilment that would promote learners' learning transfer. In view of previous studies, it has been found that most of them are concerned with the application of ARCS model in different disciplines [13-15], online learning such as MOOCs [16-19]. Some of the application studies in various disciplines are case studies that focus on the application of ARCS model to scientific and technological courses [20-23] and basic theoretical courses [24-25]. However, few studies have been found in relation to the application of ARCS model to CBEC course design and its effect. 
With regard to the studies on CBEC course, most studies come along with the development of global e-business. Some of the studies concentrate on the general discussion of teaching strategies such as CLIL [26] and PBL [8]. Some of the studies focus on the educational reforms [27-28]. It is hardly to find the study which analyse the learners' motivation in CBEC course from the perspective of ARCS model. The students' motivation in the course is definitely worthy of study since the output of course learning could directly provide excellent candidates for CBEC companies that are at present in shortage of professional workforce. Therefore, this study intends to analyse the effect of the application of ARCS motivation model [12] in CBEC course design. Hopefully, the study results would provide some implications for CBEC course design and teaching.

\section{METHODOLOGY}

\subsection{Research Purposes}

This study aims to carry out a case study to analyse the application of ARCS model [12] to CBEC course. The following two research questions are guided through the study: 1) What are the features of CBEC course designed on the basis of ARCS model? 2) What are the effects of the ARCS motivational course design?

By answering these two questions, hopefully, this study would offer some insights to the CBEC teaching and researching. Meanwhile, it would validate the effect of ARCS model application to a new course.

\subsection{Research Subjects}

The research subjects are juniors from Xinhua College of Sun Yat-sen University majoring in English, Spanish and Portuguese. The semester is Fall in 2019. The CBEC course is an elective that was determined at the end of their sophomore year. The total number of learners in this course is 103, with 15 males and 88 females. The questionnaire randomly took a sample of 37 students, among whom there were 31 female and 6 male students. The gender ratio of sample is roughly the same as that of students in whole class.

The course for whole semester involves 18 weeks. Since the last two weeks were for final presentation and assessment, 16 weeks were designed for application of ARCS model [12], including eight units introduction to CBEC, platforms rules, product selection, product posting, logistics, product optimizing, marketing and after-sale services. The basic schedule was one unit for two weeks with slight adjustment.

\subsection{Research Methods}

Qualitative and quantitative methods were both employed for analysis. A case study of juniors in Xinhua College of Sun Yat-sen University is taken for qualitative analysis while a questionnaire survey was carried out for quantitative analysis.

The questionnaire was designed based on ARCS model [12] with Likert 5 scales for questions in relation to attitudes. Due to the different teaching environment from Keller's, the activities mentioned in Kellers' works were not totally taken. We adjusted the course design according to the requirements of CBEC talents in Chinese society. All together there are 10 questions regarding attitudes towards the course design and teaching tactics. The value of Cronbach a is 0.66 , which means the data obtained from the questionnaire is reliable for analysis.

\subsection{Research Procedure}

The study was carried out at the end of the semester after the final score of this course has been given. The questionnaire was totally anonymous. The reason for this is that students could authentically answer the questionnaire without fear of affecting their final scores. After the data was collected, it was analysed online for further analysis.

\section{RESULTS ANALYSIS}

The syllabus of CBEC was designed based on the four elements of ARCS model: attention, relevance, confidence and satisfaction [12]. With regard to CBEC, it is an interdisplinary course involving foreign languages, international trade, operation of e-commerce platform, logistics and marketing.

Considering the majors and capability of juniors, the allocation of class was adjusted according to the difficulty of teaching units. The students majoring in foreign languages were especially given more time on the units such were challenging for them as logistics setting.

According to the questionnaire survey, $89.2 \%$ of research subjects believe that the whole semester's learning is "rewarding" and "very rewarding". This indicates that the CBEC course designed based on the ARCS model can satisfy the learning needs of most students.

In the course design, the following four teaching tactics are the features on the basis of ARCS motivational model [12].

\subsection{Team Based Learning: Mini-company Participation}

Team Based Learning (hereinafter as TBL) was initially developed in business school and then has been employed in diverse teaching context, especially the medical 
education [28]. It refers to the strategy that students voluntarily group together as a mini company during the whole semester. As a company, they need to elect a CEO who is responsible for the entire team's business including profits and loss. Besides, the participation in class, homework assignment and final assessment were all in group form. In other words, it means that there was no individual score for their personal performance in these sections but only group score for them all.

This differs from the traditional TBL in that, considering the practice-focused CBEC course, it is based on the R1, $\mathrm{C} 2, \mathrm{~S} 1$ and S2 strategies in ARCS model [12] to engage the students in the form of mini-company.

Based on R1 Goal Orientation strategy, the setup of mini-company can satisfy the students' needs of real engagement in the business activity. The team members are connected as a whole since their participation in class and accomplishment of assignments after class were assessed as one participant in the course.

According the questionnaire survey, the respondents of question "How do you think of getting score as a group?" are largely in favour of this strategy with $67.6 \%$ choosing "satisfied" or "very satisfied". The rest of them chose "average". No one regarded it as "unsatisfied". This reveals that adjusted TBL is suitable for students in CBEC class.

According to $\mathrm{C} 1$ Learning Requirements strategy in Confidence element [12], different teams were assigned with diversified homework and goals. For instance, when uploading products, the basic requirement for the number of products is 50 . For those teams with relatively more members, the number will be larger. Meanwhile, in accordance to the R1 and S2 strategies [12], students are encouraged to upload more in that more products offer larger chance of getting orders. When uploading the products, the score given by the CBEC trading platform has to be above 80 and the highest is 100 . In this way, the immediate feedback given by the trading platform could be motive for students to improve and attain their goals.

$\mathrm{R} 1, \mathrm{~S} 1$ and S2 strategies [12] are revealed in another aspect which is to inform the students of completing at least one order within the semester. The expected order is supposed to bring profits to the mini-company, which is the S2 strategy in Satisfaction element [12]. The profits serve as the positive consequence of their learning process. Nevertheless, there might be some loss as well, which is the natural consequence of any business in reality. Even though students were aware of this consequence, their confidence was not affected. On the contrary, by interviewing some course learners, the problems in their CBEC operation actually boosted their confidence for the reason that they at least selected the products that were in buyers' taste. With this regard, they felt superior to those students who had no order yet. At the same time, the problems would make them aware of how to do better in their operation of store online. This is teaching tactic implied by $\mathrm{C} 3$ Personal Control in ARCS model [12].

\subsection{Real Trading Platform}

In the course design, real CBEC trading platform DHgate is selected for practice. Actually, with the development of CBEC industry, changes are always taking place. There are free and charged CBEC platforms. Apart from these, there are simulated ones of those charged platforms. For CBEC course, multiple choices are out there but in the guidance of ARCS model, especially the Satisfaction element [12], DHgate was chosen for students' practice. Students have to learn about rules in DHgate, upload products and operate their store online. The team members work together to achieve the goal of completing one order at least. As is mentioned in Section 4.1, there might be profit or loss in their business. When the mini-company earns, a sense of pride would come along, which can boost the confidence actually since the success opportunity comes true. However, the risk of entering e-commerce fraud [29] would bring challenges to the mini-company. They have to endeavour in every aspect so as to identify the true buyers and conduct profitable business. For example, when setting the price, students had to calculate the cost and logistics fees very carefully since they needed to prepare the products by themselves with their own finance. Before that, students had to carefully select the proper products that could be sold. After uploading the products, they would adjust the products according to its visitors and exposure. Sometimes, they would carry out some sales plans. Each step had to be taken very carefully due to the real trading platform. They were dealing with factories, buyers, logistic companies and so on. All these actually comply with the C3 Personal Control strategy in Confidence element of ARCS model [12], which is very important in their operation of global business online.

In the questionnaire survey about the practice in real CBEC platform, the average score is 4.03 which means this course design is acceptable for the majority of the students. $69.3 \%$ of the subjects love to operate in real business platform. The numbers show that real trading platform could boost the satisfaction and confidence in students which is very crucial for maintaining students' learning motivation.

\subsection{Adequate Practice in Class}

The practice in class is actually nothing new. For many courses, practices in class are very extensive. What is specially emphasized in the CBEC class is that every week half of the class time is given for practice. This is based on the Attention Getting strategy in ARCS model [12]. It would be definitely a boring class when teachers spent most of time on instructing. Actually, for CBEC, so much could be obtained online by students themselves. According to the A2 Inquiry Arousal strategy [12], questions were proposed in teachers' classroom instruction and students could solve the problems in their practice. It would be better for maintaining students' attention in class. 
What's more, enough practice in class is on the basis of the Relevance element in the motivational model [12]. In students' practice in real platform, the information given by teachers was properly applied to their online store operation, which also reveals the value of teacher's instruction.

The questionnaire results show that $81 \%$ of the subjects accept more practice in class. $16 \%$ of them regard the practice in class "not enough" and 3\% of them think the practice time is "little". This implies that students enjoy practice in class and they are in favour of more practice in class. In the future course teaching, more time should be allocated for practice.

Practice in class was also guided with some tasks and students were encouraged to accomplish them as soon as possible. The more quickly they finished their task, the more classroom performance score they would obtain. This tactic is based on the Confidence element in ARCS model [12]. Class requirements are notified and students are aware of their success opportunities in that their quick and efficient team work would earn more score for their classroom performance. They are totally in control of their group work. According to the questionnaire results, 91.1\% of the subjects are (very) satisfied with this strategy with. This will be mentioned as well in the next section.

\subsection{Timely Feedback in Public}

The importance of feedback in teaching is widely acknowledged [30]. In the course design of CBEC, considering the real trading platform and requirement of enough practice, feedback is given in public and most importantly in time. This teaching strategy is based on the Satisfaction and Relevance elements in ARCS model [12]. Teacher gives excellent students or mini-company oral and public positive appraisal. This would set other students an example to follow. Learning from fellow students would be more inspiring for students to sustain their learning. Offering timely feedback is in line with the S2 Positive consequences strategy in that students would quickly realize whether they have reached their expectation. For those students who endeavour a lot into their learning, the timely feedback would make them feel worthy and thus enhance their confidence. As is stated in Section 4.3, the faster students accomplish their task, the more score they get for their classroom performance. This strategy is welcomed among students with only $8.1 \%$ of the research subjects think it average.

For homework assignments, teacher would make sure their feedback would be given within one week after class, occasionally two weeks. Class time is not enough for practice. Thus, homework has to be assigned for better mastering of skills in CBEC. Without the immediate feedback, students might be less motivated. Thus, it is very important to keep students motivated after class. Quick feedback of homework is necessary. Just like the feedback in class, for those who have finished their work quickly, more score will be given for their participation.
According to the questionnaire, when it comes to whether the teacher has offered feedback in time, $48.6 \%$ choose "very timely" and $43.2 \%$ think "timely". An overwhelming majority of students approve of the timely feedback. One week feedback is very referential for CBEC course design.

\section{CONCLUSION}

With regard to the analysis above, it can be seen that the CBEC course design based on ARCS model could effectively attain students' attention, produce relevance, build confidence and generate satisfaction. Most of the teaching strategies were based on Confidence and Satisfaction elements [12]. Those two elements were also two important factors that would keep students motivated. In the course design, adjusted TBL, real trading platform, enough practice in class and teachers' public and timely feedback are the main features on the basis of the ARCS motivational model. In designing the CBEC course, teaching strategies that combines more than one element in the ARCS motivational model are recommended.

In the questionnaire survey, it is also found that some strategies need to be strengthened in the future such as the Goal Orientation strategy [12]. According to the results, over half of the subjects believe that they were not sure about their capability in entering CBEC companies whether as employees or interns. In other words, they were not fully aware that their learning of skills in class at present would help them achieve certain goal in the future. The future value of the course was not emphasized. This could be amended in the future course design. Besides, this study is insufficient in the number of subjects. Future studies can involve more students in the survey.

To sum up, this study has enriched previous research in relation to ARCS model by taking a new case for study and extended its application to CBEC course. The analysis of course design is also referential to the teaching and researching in CBEC.

\section{ACKNOWLEDGMENT}

This work was supported by Key Courses in Xinhua College of Sun Yat-sen University: CBEC Practice (2018ZD002), Guangdong Province Project Study on the Mode of CEBT Talent Cultivation based on school-enterprise cooperation for Business English Undergraduate Program in the Application-oriented Colleges under "The Belt and Road Initiative" (2017GXJK231) and Guangdong Province Project Study on the Design and Application of CBEC After-sales Service Communication 
Psychology, 25 (1) (2000) 68-81. DOI: https://doi.org/10.1006/ceps.1999.1015

[10] M. A. Hogg, D. Abrams, S. Otten, S. Hinkle, The Social Identity Perspective. Small Group Research, 35(3) (2004) 246-276. DOI: https://doi.org/10.1177/1046496404263424

[11] J.M. Keller, Development and use of the ARCS model of instructional design. Journal of Instructional Development, 10 (2) (1987) 2-10. DOI: https://doi.org/10.1007/BF02905780

[2] Z. Liu, Z. Li, A blockchain-based framework of cross-border e-commerce supply chain, International Journal of Information Management, (2019). DOI: https://doi.org/10.1016/j.ijinfomgt.2019.102059.

[3] S. Ren, T-M. Choi, K-M. Lee, L. Lin, Intelligent service capacity allocation for cross-border-E-commerce related third-party-forwarding logistics operations: A deep learning approach, Transportation Research Part E: Logistics and Transportation Review, 134 (2020). DOI: https://doi.org/10.1016/j.tre.2019.101834

[4] Y-H. Hsiao, M-C. Chen, W-C. Liao, Logistics service design for cross-border E-commerce using Kansei engineering with text-mining-based online content analysis, Telematics and Informatics, 34 (4) (2017) 284-302. DOI: https://doi.org/10.1016/j.tele.2016.08.002

[5] X. Qi, J. H. Chan, J. Hu, Y. Li, Motivations for selecting cross-border e-commerce as a foreign market entry mode, Industrial Marketing Management, (2020). DOI: https://doi.org/10.1016/j.indmarman.2020.01.009.

[6]. Y. Cui, J. Mou, J. Cohen, Y. Liu, K. Kurcz, Understanding consumer intentions toward cross-border $\mathrm{m}$-commerce usage: A psychological distance and commitment-trust perspective, Electronic Commerce Research and Applications, 39 (2020) . DOI: https://doi.org/10.1016/j.elerap.2019.100920.

[7] L. J. Delaney, Finding Cross-Border Customers. In: Exporting. Apress, Berkeley, CA, 2013. DOI: https://doi.org/10.1007/978-1-4302-5792-9_16

[8] X. Cheng, L. Su, A. Zarifis, Designing a talents training model for cross-border e-commerce: a mixed approach of problem-based learning with social media, Electron Commer Res. 19 (2019) 801-822 . DOI: https://doi.org/10.1007/s10660-019-09341-y

[9] A. Wigfield, J. S. Eccles, Expectancy-Value Theory of Achievement Motivation, Contemporary Educational
[12] J. M. Keller, Motivational Design for Learning and Performance, Springer, 2010. DOI: https://doi.org/10.1007/978-1-4419-1250-3

[13] J. Visser, J. M. Keller, The clinical use of motivational messages: an inquiry into the validity of the ARCS model of motivational design, Instr. Sci. 19 (1990) 467-500. DOI: https://doi.org/10.1007/BF00119391

[14] A. Tlili, F. Essalmi, M. Jemni, Kinshuk, Towards Applying Keller's ARCS Model and Learning by doing strategy in Classroom Courses, in: Popescu E. et al. (Eds.), Innovations in Smart Learning. Lecture Notes in Educational Technology, Springer, Singapore, 2017, pp.187-196. DOI: https://doi.org/10.1007/978-981-10-2419-1_26

[15] I-C. Hung, L. Lee, K-J. Chao, NS, Chen. Applying ARCS Model for Enhancing and Sustaining Learning Motivation in Using Robot as Teaching Assistant, in: M. Chang, W-Y. Hwang, M-P. Chen, W. Müller (Eds), Edutainment Technologies, Educational Games and Virtual Reality/Augmented Reality Applications. Edutainment 2011, Lecture Notes in Computer Science, vol. 6872, Springer, Berlin, Heidelberg, 2011. DOI: https://doi.org/10.1007/978-3-642-23456-9_6

[16] S. Zheng, M. B. Rosson, P. C. Shih, J. M. Carroll, Understanding student motivation, behaviors and perceptions in MOOCs, in: Proceedings of the 18th ACM Conference on Computer Supported Cooperative Work \& Social Computing, New York, ACM, 2015, pp. 1882-1895. DOI: https://doi.org/10.1145/2675133.2675217

[17] H. B. Shapiro, C. H. Lee, N. E. W. Roth, K. Li, M. Cetinkaya-Rundel, D. A. Canelas, Understanding the massive open online course (MOOC) student experience: an examination of attitudes, motivations, and barriers. Computers \& Education, 110 (2017) 35- 
about Acids and Bases. Int J Sci Math Educ. 3 (2005) 463-484. DOI: https://doi.org/10.1007/s10763-004-6828-7

[18] K. Li, D.R. Moore, Motivating Students in Massive Open Online Courses (MOOCs) Using the Attention, Relevance, Confidence, Satisfaction (ARCS) Model. J Form Des Learn, 2 (2018) 102-113. DOI: https://doi.org/10.1007/s41686-018-0021-9

[19] D-F. Huang, Effects of the Online VOD Self-learning on English Ability of Taiwanese College Students: The ARCS Approach, in: Y-M. Huang, H-C. Chao, DJ. Deng, J. Park (Eds.), Advanced Technologies, Embedded and Multimedia for Human-centric Computing, Lecture Notes in Electrical Engineering, vol. 260, Springer, Dordrech, 2014, pp.1009-1015. DOI: https://doi.org/10.1007/978-94-007-7262-5_115

[20] B. Shellnut, A. Knowltion, T. Savage, Applying the ARCS model to the design and development of computer-based modules for manufacturing engineering courses, ETR\&D. 47(1999) 100-110. DOI: https://doi.org/10.1007/BF02299469

[21] K. K. Daugherty, ARCS motivation model application in a pharmacy elective, Currents in Pharmacy Teaching and Learning, 11(12) (2019) 1274-1280. DOI: https://doi.org/10.1016/j.cptl.2019.09.009

[22]. C. Chang, C-K. Chang, J-L. Shih, Motivational strategies in a mobile inquiry-based language learning setting, System, 59 (2016) 100-115. DOI: https://doi.org/10.1016/j.system.2016.04.013

[23]. V. Karampa, F. Paraskeva, A Motivational Design of a Flipped Classroom on Collaborative Programming and STEAM, in: L. Uden, D. Liberona, J. Ristvej (Eds.) Learning Technology for Education Challenges, LTEC 2018, Communications in Computer and Information Science, vol. 870, Springer, Cham, 2018, pp. 226-238. DOI: https://doi.org/10.1007/978-3-319-95522-3_19

[24] C-T.Hou, C-L. Wu, The Effects of Teaching Mathematics to Students with Disabilities Using Multimedia Computer-Assisted Instruction Coupled with ARCS Model, in: K. Miesenberger, A. Karshmer, P. Penaz, W. Zagler (Eds.) Computers Helping People with Special Needs, ICCHP 2012, Lecture Notes in Computer Science, vol. 7382, Springer, Berlin, Heidelberg, 2012, pp. 204-206. DOI: https://doi.org/10.1007/978-3-642-31522-0_30

[25] S. Feng, H. Tuan, Using ARCS Model to Promote 11th Graders' Motivation and Achievement in Learning
[26] Y. Jing, The Teaching Practice of the Cross-Border E-Commerce to Business English Majors in Vocational and Technical Colleges: A Study Based on the Theory of CLIL, in: Y. Kim (Ed.), Proceedings of International Conference on Social Science and Technology Education, ICSSTE 2016, Advances in Social Science Education and Humanities Research, vol. 55, Int Assoc Cyber Sci \& Engn, Guangzhou, 2016, pp. 683-686.

[27] H-X. Wang, Research on the Teaching Reform of Cross-border E-Commerce Course Based on the Double-increment Ability Training, in: X. Du, C. Huang, Y. Zhong (Eds.), Proceedings of the $20184^{\text {th }}$ International Conference on Humanities and Social Science Research, CHSSR 2018, Advances in Social Science Education and Humanities Research, vol. 213, Jiangnan Univ, Int Acad Exchange Ctr, Wuxi, 2018, pp. $842-845$

[28] S-S. Liu, Research on Business English Teaching Reform in Colleges and Universities Based on Cross-border E-commerce, in: J. Gao (Ed.), 2019 International Conference on Arts, Management, Education and Innovation, ICAMEI 2019, Seoul, 2019, pp. 556-560. DOI: $10.23977 /$ icamei.2019.108

[29] B. Roman, C. Hayden, D. Parmelee, The Effectiveness of Engaged Learning: 8 Years of TBL in Internal Medicine and Psychiatry Clerkships, Med.Sci.Educ. 27 (2017) 475-479. DOI: https://doi.org/10.1007/s40670-017-0412-6

[30] Y. Guo, Y. Bao, B. J. Stuart, K. Le-Nguyen, To sell or not to sell: Exploring sellers' trust and risk of chargeback fraud in cross-border electronic commerce. Information Systems Journal, 28(2) (2018) 359-383. DOI: https://doi.org/10.1111/isj.12144

[31] E.J.S. Barboza, M.T. da Silva, The Importance of Timely Feedback to Interactivity in Online Education. in: I. Nääs et al. (Eds.) Advances in Production Management Systems, Initiatives for a Sustainable World, APMS 2016, IFIP Advances in Information and Communication Technology, vol. 488. Springer, Cham, 2016, pp. 307-314. DOI:

https://doi.org/10.1007/978-3-319-51133-7_37 